\title{
Systemic thrombolysis causing haemorrhage around a prosthetic abdominal aortic graft
}

\author{
Nick J M London, Bryan Williams, Andrew Stein
}

\section{Hypotension after thrombolytic \\ therapy for myocardial infarction may result from haemorrhage or anaphylaxis, and the clinician should consider these in addition to reinfarction}

\section{Leicester General \\ Hospital, Leicester LE5 4PW \\ Nick J M London, lecturer in surgery \\ Bryan Williams, lecturer in medicine \\ Andrew Stein, research fellow in nephrology}

\section{Correspondence to:}

Mr N J M London,

Department of Surgery, Clinical Sciences Building, Leicester Royal Infirmary, Leicester LE2 7LX.
A main complication of thrombolytic therapy is bleeding, which is why it is contraindicated within one week of major surgery. Indeed, the risk of bleeding after surgery may be increased for up to six weeks. ${ }^{1}$ We describe a case of haemorrhage around a prosthetic abdominal aortic graft after thrombolysis for a myocardial infarction three months after the graft had been inserted.

\section{Case report}

A 64 year old man with a history of hypertension, cerebrovascular disease, cardiac ischaemia, and analgesic nephropathy (serum creatinine concentration $480 \mu \mathrm{mol} / \mathrm{l}$ ) was admitted as an emergency case with abdominal pain and hypotension. A leaking abdominal aortic aneurysm was diagnosed. At operation there was a large haematoma around a ruptured $7 \mathrm{~cm}$ abdominal aortic aneurysm and the aorta was replaced with a woven Dacron tube graft. His postoperative recovery was complicated by the development of chronic renal failure. This was managed by regular haemodialysis, which was subsequently continued as an outpatient.

Three months after his abdominal aortic aneurysm repair he had just arrived for haemodialysis when he suffered a cardiac arrest. Cardiac monitoring showed ventricular fibrillation, which responded to DC shock. A formal electrocardiogram suggested an evolving myocardial infarction and he was transferred to the intensive care unit. Systolic blood pressure was $140 \mathrm{~mm} \mathrm{Hg}$. Intravenous streptokinase (1.5 MU over one hour) was given. He did not receive aspirin or subcutaneous heparin. Two hours later he became shocked and his systolic blood pressure fell to $50 \mathrm{~mm}$ $\mathrm{Hg}$. An extension of the myocardial infarction was suspected and tissue-type plasminogen activator ( $10 \mathrm{mg}$ bolus, followed by $50 \mathrm{mg}$ over one hour) was given.

The patient's condition continued to deteriorate and his systolic blood pressure dropped to $40 \mathrm{~mm} \mathrm{Hg}$. Intravenous dobutamine $(4 \mu \mathrm{g} / \mathrm{kg} / \mathrm{min})$ and colloid were required to maintain a systolic blood pressure of $80 \mathrm{~mm} \mathrm{Hg}$. It was then noted that his vascular access sites were bleeding and that his abdomen was distended. Fine needle aspiration of the peritoneal cavity at three points yielded fresh blood, and an urgent ultrasound examination showed both free intraperitoneal fluid and a large perigraft midline retroperitoneal fluid collection. A coagulation screen showed an international normalised ratio of $4 \cdot 1$ (normal $1 \cdot 0-1 \cdot 2$ ), a fibrinogen concentration of $0.6 \mathrm{~g} / \mathrm{l}(1 \cdot 5-4 \cdot 0)$, and a concentration of fibrinogen degradation products of $4000 \mu \mathrm{g} / \mathrm{l}$ (100-500); haemoglobin concentration was $50 \mathrm{~g} / \mathrm{l}$ (previously $90 \mathrm{~g} / \mathrm{l}$ ).

A diagnosis of perigraft retroperitoneal haemorrhage was made and the thrombolysis reversed with a combination of intravenous aprotinin (500 000 kallidinogenase inactivating units over 10 minutes, followed by 200000 units hourly), intravenous tranexamic acid ( $10 \mathrm{mg} / \mathrm{kg}$ over 10 minutes), four units of fresh frozen plasma, and six units of cryoprecipitate. The patient's condition rapidly improved and four hours later the systolic blood pressure was stable at $130 \mathrm{~mm} \mathrm{Hg}$. A repeat coagulation screen showed an international normalised ratio of $1 \cdot 6$, a fibrinogen concentration of $2 \cdot 2 \mathrm{~g} / \mathrm{l}$, and a concentration of fibrinogen degradation products of $4000 \mu \mathrm{g} / \mathrm{l}$. The blood loss was replaced with five units of whole blood given over the next 24 hours. The patient made a full recovery and was discharged home to continue outpatient haemodialysis. Serial electrocardiograms and serum cardiac enzyme activities were consistent with the initial diagnosis of myocardial infarction.

\section{Discussion}

Although the overall benefits of thrombolytic agents in acute coronary thrombosis are firmly established, ${ }^{12}$ it is well recognised that bleeding can occur in up to $10 \%$ of patients, of whom one fifth ( $2 \%$ of all patients) require transfusion. ${ }^{1}$ The commonest site of bleeding is the gastrointestinal tract, ${ }^{1}$ the incidence of retroperitoneal bleeding being reported as $0.5 \% .^{3}$ The association between coronary artery disease and abdominal aortic aneurysm is such that $94 \%$ of patients with abdominal aortic aneurysms have abnormal coronary arteriograms $\mathrm{s}^{4}$ and $45 \%$ have symptomatic coronary artery disease. ${ }^{5}$ Thus an appreciable number of patients presenting with acute myocardial infarction have had an abdominal aortic aneurysmectomy and prosthetic graft insertion.

There are few published data on the risk of bleeding from vascular grafts during systemic thrombolysis. In the case of regional thrombolytic therapy contrast reportedly extravasated through knitted Dacron grafts during low dose intra-arterial streptokinase therapy, ${ }^{6}$ and it has been suggested that intra-arterial thrombolytic therapy is contraindicated within six months of the implantation of retroperitoneal grafts.

There are two basic types of vascular graft-knitted and woven. ${ }^{8}$ Knitted grafts have a loose weave, and their initial integrity depends on mural thrombus. After about 12 weeks fibroblasts penetrate the fabric, and by about six months the graft is incorporated into the tissues. Woven grafts have a tighter weave, do not rely heavily on mural thrombus for their integrity, and do not become incorporated into the tissues but instead lie in a periprosthetic capsule. Thus theoretically it might be expected that thrombolysis would be more likely to cause bleeding through the interstices of knitted grafts than through the interstices of woven grafts.

A further consideration is the integrity of the anastomoses. In the case of woven grafts, because they do not become fully incorporated into the surrounding tissues late anastomotic integrity may rely on thrombus formation. By contrast, in the case of knitted grafts anastomotic integrity will be provided by tissue incorporation. It may therefore be postulated that the risk of anastomotic bleeding during thrombolysis is greater with woven than with knitted grafts and that this risk may persist indefinitely. Finally, in the case of grafts inserted for ruptured abdominal aortic aneurysms there is usually a large retroperitoneal 
haematoma that may take many weeks to fully resolve. Systemic thrombolysis in this setting might be expected to lead to non-specific bleeding from retroperitoneal vessels.

Although the exact site of bleeding in our patient remains conjectural, the combination of a large blood loss in the presence of a woven graft would make anastomotic bleeding more likely than bleeding through the graft interstices. We cannot find a previous report of this complication during systemic thrombolysis, and in view of the proved benefits of systemic thrombolysis we do not consider the presence of a prosthetic aortic graft an absolute contraindication to its use.

There are several lessons to be learnt from this case. Firstly, hypotension after treatment with a thrombolytic agent for myocardial infarction may result from various causes, including haemorrhage and anaphylaxis, and the clinician should consider these possibilities in addition to reinfarction. Thus, although combination thrombolytic therapy for myocardial infarction is well described, ${ }^{9}$ a higher index of suspicion of the possibility of haemorrhage in our patient might have prevented the inappropriate use of tissue-type plasminogen activator. The second lesson is to consider covert retroperitoneal haemorrhage after systemic thrombolysis in patients with prosthetic abdominal aortic grafts. An abdominal ultrasound examination may confirm the diagnosis, and once recognised the patient should be resuscitated by reversing the thrombolysis, introducing blood products, and carefully replacing the lost blood volume. Finally, because it is not known for how long after surgery the risk of haemorrhage during systemic thrombolysis persists clinicians giving this treatment should constantly be aware of the possibility of a haemorrhagic complication in postoperative patients.

We are grateful to Professor J Walls and Dr J Feehally for allowing us to report this case.

1 Taylor GJ. Thrombolytic therapy for acute myocardial infarction. Boston: Blackwell Scientific, 1992.

2 ISIS-2 (Second International Study of Infarct Survival) Collaborative Group. Randomised trial of intravenous streptokinase, oral aspirin, both or neithe among 17187 cases of suspected acute myocardial infarction: ISIS-2. Lance 1988;ii:349-60.

3 Ellis SG. Interventions in acute myocardial infarction. Circulation 1990;8 (suppl IV):43-50.

4 Hertzer NR, Beven EG, Young JR, O'Hara PJ, Ruschhaupt WF, Graor RA. Coronary artery disease in peripheral vascular patients: a classification of 1000 coronary angiograms and results of surgical management. Ann Surg 1984;199: 223-33.

5 Johnson KW, Scobie TK. Multicentre prospective study of nonruptured abdominal aortic aneurysms. 1. Population and operative management. f Vasc Surg 1988;7:69-81.

6 Rabe FE, Becker GJ, Richmond BD, Yune HY, Holden RW, Dilley RS, et al Contrast extravasation through Dacron grafts: a sequela of low-dose streptokinase therapy. $A f R$ 1982;138:917-20.

7 Hamilton G, Dawson K. Thrombolytic therapy for acute vascular emergencies In: Greenhalgh RM, Hollier LH, eds. Emergency vascular surgery. London: Saunders, 1992:37-54.

8 Smith SRG. The principles underlying graft selection for arterial reconstruction. Br F Hosp Med 1987;38:358-63.

9 Grines CL, Nissen SE, Booth DC, Gurley JC, Chelliah H, Wolf R, et al. A prospective, randomised trial comparing combination half dose tissue-type plasminogen activator and streptokinase with full dose tissue-type plasminogen activator. Circulation 1991;84:540-9.

(Accepted 18 February 1993)

\section{A PATIENT WHO CHANGED MY PRACTICE}

\section{Aspirate an abscess rather than incise it}

When I suspected that a woman had a breast abscess it had become my standard practice to perform an initial aspiration to confirm the presence of pus before proceeding to incise and drain it.

Then a patient presented with what I believed was a localised abscess and so I inserted a needle into the lesion and aspirated $15 \mathrm{ml}$ of pus. The mass disappeared completely, which was fortuitous because the woman was keen to avoid immediate surgery as she had difficult home circumstances. I agreed that she should continue her antibiotics and that I would see her in a couple of days' time. I told her that if the abscess refilled I thought it should be incised and drained. She came back two days later and although the abscess had refilled, the erythema had completely disappeared. I was not certain what to do. Should I try and aspirate the abscess again or drain it surgically? I asked $\mathrm{Mr}$ Malcolm Gough, the senior surgeon at the John Radcliffe Hospital in Oxford. His view was clear-I should reaspirate the abscess and continue doing so at regular intervals until it resolved. Meanwhile the woman should continue to take antibiotics and to breast feed if she wished. I aspirated the abscess twice more and it resolved.

Since then I have managed many breast abscesses in women who were breast feeding without having to drain any of them under general anaesthesia. All have resolved. I have treated many abscesses by aspiration with equal success in women who were not breast feeding. The only difference is that I combine regular aspiration with oral co-amoxiclav or a combination of cephradine and metronidazole rather than the flucloxacillin I use in lactating patients. There are some abscesses in which the skin overlying the abscess is very thinned and in these cases I apply local anaesthetic cream which I leave in place for an hour and then make a small incision through the thinned skin. I then apply a dry dressing. I have encouraged all patients who develop abscesses when breast feeding to persist if they wish and over half have continued to do so successfully.

The first report of treating small abscesses by aspiration and installation of antibiotics into the cavity was published in the $B M F$ in $1946^{\prime}$ so what I am doing is not new. Only last week, however, a mother and her child flew to Edinburgh because the London teaching hospital would not consider either aspirating her abscess or permitting her to continue to breast feed once drainage for the abscess had been instituted.-MICHAEL DIXON is a senior lecturer in surgery in Edinburgh

1 Florey ME, Macvine JS, Bigby MAM. Treatment of breast abscesses with penicillin. $B M 7$ 1946; ii:846-8.

We are delighted to receive submissions of up to 600 words on $A$ paper (or patient or book) that changed my practice, $A$ memorable patient, The one message I would like to leave behind, or related topics. 